\title{
Fission-Based Electric Propulsion for Interstellar Precursor Missions
}

\author{
Ronald J. Lipinski ${ }^{1}$, Roger X. Lenard ${ }^{1}$, Steven A. Wright ${ }^{1}$, Michael G. Houts ${ }^{2}$, \\ Bruce Patton ${ }^{2}$, and David Poston ${ }^{3}$ \\ 'Sandia National Laboratories, MS-1146, P.O. Box 5800, Albuquerque, NM 87185, rjlipin@sandia.gov \\ ${ }^{2}$ Marshall Space Flight Center, Huntsville, AL, 35812, michael.houts@msfc.nasa.gov \\ ${ }^{3}$ Los Alamos National Laboratory, Los Alamos, NM 87545, poston@lanl.gov
}

\begin{abstract}
This paper reviews the technology options for a fission-based electric propulsion system for interstellar precursor missions. To achieve a total $\Delta \mathrm{V}$ of more than $100 \mathrm{~km} / \mathrm{s}$ in less than a decade of thrusting with an electric propulsion system of $10,000 \mathrm{~s}$ Isp requires a specific mass for the power system of less than $35 \mathrm{~kg} / \mathrm{kWe}$. Three possible configurations are described: (1) a UZrH-fueled, NaK-cooled reactor with a steam Rankine conversion system, (2) a UNfueled gas-cooled reactor with a recuperated Brayton conversion system, and (3) a UN-fueled heatpipe-cooled reactor with a recuperated Brayton conversion system. All three of these systems have the potential to meet the specific mass requirements for interstellar precursor missions in the near term. Advanced versions of a fission-based electric propulsion system might travel as much as several light years in 200 years.
\end{abstract}

\section{INTRODUCTION}

Interstellar precursor missions are those which stretch our technical capabilities in the directions needed for later interstellar travel. Nominally they involve missions to beyond Pluto with trip time of less than 20 years and velocities of over $50 \mathrm{~km} / \mathrm{s}$. Two potential near-term interstellar precursor missions are a Kuiper Belt Object rendezvous mission and a Heliopause Probe mission. Kuiper Belt Objects (KBOs) are a recently-discovered set of solar system bodies which lie at about the orbit of Pluto $(40 \mathrm{AU})$ out to about 100 astronomical units (AU). There are estimated to be as many as 100,000 KBOs with a diameter greater than $100 \mathrm{~km}$ (Malhotra, 1999, Jewitt, 1999). $\mathrm{KBO}$ are postulated to be composed of the pristine material which formed our solar system and may even have organic materials in them. A rendezvous mission including a lander would be needed to perform chemical analysis of the surface and sub-surface composition of KBOs. Although the distance to the KBOs is not exceedingly large, the need to accelerate, coast, and then decelerate for rendezvous results in a total mission delta-V of about $50 \mathrm{~km} / \mathrm{s}$. This places it in the precursor category. The heliopause occurs between 100-200 AU, so a mission to there in under 20 years also would require a velocity of around $50 \mathrm{~km} / \mathrm{s}$ or more. More challenging missions would require a $\Delta V$ 's of well over $100 \mathrm{~km} / \mathrm{s}$.

To achieve a velocity of $100 \mathrm{~km} / \mathrm{s}$ without a severe mass penalty for the propellant requires a specific impulse (Isp) of about $10,000 \mathrm{~s}$. Such an Isp can be achieved with electric propulsion. To achieve this velocity in about a decade with this Isp requires a specific mass for the total spacecraft of less than about $45 \mathrm{~kg} / \mathrm{kWe}$ (at $80 \%$ thruster efficiency). Subtracting off $10 \mathrm{~kg} / \mathrm{kWe}$ for the thrusters, tankage, and remainder of the spacecraft leaves about 35 $\mathrm{kg} / \mathrm{kWe}$ for the power system. Such a specific power can be provided by near-term fission-based power systems.

Several reactor and electrical conversion systems can be envisioned. Each has different advantages depending on the available launch mass, flight time, and development time and budget. One possible power system is a SNAP-10A derivative (using $\mathrm{UZrH}$ fuel) with a steam Rankine cycle conversion system. Another is a gas-cooled reactor (using SP-100 developed UN fuel) with a Brayton conversion system. A third is a heat-pipe cooled system (with UN or UO2- fuel) and a Brayton conversion system. None of these options require any new fuels or materials development. 


\section{DISCLAIMER}

This report was prepared as an account of work sponsored by an agency of the United States Government. Neither the United States Government nor any agency thereof, nor any of their employees, make any warranty, express or implied, or assumes any legal liability or responsibility for the accuracy, completeness, or usefulness of any information, apparatus, product, or process disclosed, or represents that its use would not infringe privately owned rights. Reference herein to any specific commercial product, process, or service by trade name, trademark, manufacturer, or otherwise does not necessarily constitute or imply its endorsement, recommendation, or favoring by the United States Government or any agency thereof. The views and opinions of authors expressed herein do not necessarily state or reflect those of the United States Government or any agency thereof. 


\section{DISCLAIMER}

Portions of this document may be illegible in electronic image products. Images are produced from the best available original document. 
But they all require good engineering, testing, and integration. The various options and growth potential for the power system will be described and compared for the interstellar precursor missions.

\section{SYSTEM ANALYSIS}

To achieve the velocities needed for interstellar precursor missions (i.e., $>100 \mathrm{~km} / \mathrm{s}$ ) in times acceptably short for such missions (i.e., $<20$ years) requires both a high specific impulse and an adequately high acceleration (or thrustto-mass ratio). The rocket equation (Sutton, 1986) dictates that the total mass of fuel needed increases exponentially with the ratio of the desired velocity increase $(\Delta \mathrm{V})$ over the specific impulse of the fuel (Isp) times the gravitational acceleration on earth $(\mathrm{g})$ :

$$
m_{\text {fuel }}=m_{\text {nonfuel }}(\exp (\Delta V /(g I s p)-1)
$$

where $m_{\text {fuel }}$ is the mass of the propellant, $m_{\text {nonfuel }}$ is the mass of everything that is not propellant (scientific payload, communications, guidance, rocket engines, power supply, etc.). One of the best current chemical propellants is liquid oxygen/liquid hydrogen which has a specific impulse of 460 seconds. To achieve a total $\Delta \mathrm{V}$ of $100 \mathrm{~km} / \mathrm{s}$ with a payload, power system, engines, and other inert masses ("non-fuel mass") of $5000 \mathrm{~kg}$ would require 21 billion tonnes of fuel. Clearly, chemical propellants cannot do the job. But NASA has recently developed very reliable electric propulsion units with a demonstrated specific impulse of $3300 \mathrm{~s}$ (Polk, 1998). An even higher Isp can be achieved either by using a larger voltage on the grids or by using a lighter gas. NASA is also developing a VASIMR electric thruster which is projected to achieve up to $20,000 \mathrm{~s}$ Isp (Chang Diaz, 1998). To reach a total $\Delta \mathrm{V}$ of 100 $\mathrm{km} / \mathrm{s}$ with a specific impulse of 10,000 seconds and $5000 \mathrm{~kg}$ of payload and structure requires only 8.9 tonnes of propellant. This is much more reasonable.

Electric propulsion requires very large amounts of electrical energy. Nuclear fission, in the form of a small researchsized reactor, is a near-term means for obtaining this energy. A fission reactor and power conversion system for space (excluding the radiator) would be about the size of an automobile and similar in power to research reactors found at many universities. The specific mass of the power system and other non-fuel portions of the spacecraft dictates how long it takes to accelerate to $100 \mathrm{~km} / \mathrm{s}$. This determines the time required to reach a given distance. For example, if the total non-fuel mass of the spacecraft is $5000 \mathrm{~kg}$, and it delivers $250 \mathrm{~kW}$ of electrical power, the dry spacecraft has a total specific mass of $20 \mathrm{~kg} / \mathrm{kWe}$. If the electric thrusters are $75 \%$ efficient with an Isp of $10,000 \mathrm{~s}$, the spacecraft would have a maximum acceleration of

$$
a=\frac{2 \eta P}{\mathrm{~m}_{\mathrm{d}} g I_{s p}}=7.6 \times 10^{-4} \mathrm{~m} / \mathrm{s}^{2}=78 \text { microgees }
$$

where $P$ is the electrical power, $\eta$ is the thruster efficiency, $m_{d}$ is the dry mass, $g$ is the gravitational acceleration on earth, and Isp is the specific impulse. With this acceleration (or thrust-to-weight ratio), it would take 4.2 years to accelerate up to $100 \mathrm{~km} / \mathrm{s}$ (disregarding the retarding force of the sun and the initial earth-orbital velocity of $29 \mathrm{~km} / \mathrm{s}$ around the sun). This suggests that the power system needs to have a specific mass of around $20 \mathrm{~kg} / \mathrm{kWe}$ or less to obtain acceptable acceleration times.

There are two general approaches to fission-based electric propulsion precursor missions. The first approach is to launch the spacecraft into earth orbit and use the electric propulsion system to propel the spacecraft out of earth orbit and then on to interstellar space. The second approach is to launch the spacecraft into an earth-escape trajectory (called a C $3=0$ trajectory) and then use the electric propulsion system. The advantage of an earth-orbit launch is that it does not require as large a launcher for a given spacecraft weight because the highly-efficient electric propulsion system will be used to get the spacecraft out of earth's gravity well. That will reduce launch costs. A disadvantage is that it requires a longer total burn time for the reactor and electric thruster. It also requires the spacecraft to survive a relatively slow passage through the 'Van Allen radiation belt. Overcoming these difficulties is one reason to use a $\mathrm{C} 3=0$ launch. In addition, the safety analysis might be easier since reâctor'operation would not begin until an earth- 
escape trajectory is achieved. But the penalty for a $\mathrm{C} 3=0$ launch is that typically the mass that a given launcher can deliver to earth escape is about three times less mass than it can deliver to low-earth orbit.

A simple orbital mechanics code was developed and used to analyze the requirements for a $\mathrm{KBO}$ rendezvous mission, and the results are reported elsewhere in this symposium (Lipinski, 2000). That analysis showed that a $\mathrm{KBO}$ rendezvous could be achieved in 13.0 years with a $1000 \mathrm{~kg}$ science payload if the dry mass of the rest of the spacecraft (power, thrusters, navigation, communication, tankage, etc.) was $4000 \mathrm{~kg}$ and the electrical power was $100 \mathrm{kWe}$ with a thruster total efficiency of $75 \%$. The Isp for this system is $10,000 \mathrm{sec}$ and the launch mass into a C3=0 trajectory is $7984 \mathrm{~kg}$. If essentially the same spacecraft is launched into a $700-\mathrm{km}$ low-earth orbit and an additional $634 \mathrm{~kg}$ of electric-thruster propellant is added, the spacecraft can spiral out of earth orbit and rendezvous in a total of 14.3 years. With a variable-Isp thruster $(3,000$ to $10,000 \mathrm{sec})$ such as VASIMR, the trip from LEO to $\mathrm{KBO}$ rendezvous can be made in 13.5 years with a LEO launch mass of $10,300 \mathrm{~kg}$. The total $\Delta \mathrm{V}$ for the trip are $45.9,53.4$, and $53.4 \mathrm{~km} / \mathrm{s}$, respectively, for the three options.

\section{TUG DESIGN}

As described previously, the specific mass of the electric power system for interstellar precursor missions should be about $35 \mathrm{~kg} / \mathrm{kW}$ or less. This is higher in power and lower in specific mass $(\mathrm{kg} / \mathrm{kWe})$ than any space nuclear power system that has been fielded in the past, but quite reasonable for estimated masses of near-term space-reactor systems. The choice of technologies for the reactor system is fairly wide, although there is no off-the-shelf spacereactor system presently available. The SNAP program flew one space reactor in 1965 and built six other working reactors during the program. All of these used UZrH fuel with a NaK coolant (Anderson, 1983). The subsequent SP-100 program designed a reactor which used UN fuel with a Li coolant (Mondt, 1994; Mondt, 1995; El-Genk, 1994). The Russian Rorsat reactors (about 30 flown in space) used UMo fuel (Angelo, 1985). The Russian Topaz II reactor used $\mathrm{UO}{ }_{2}$ fuel and $\mathrm{UZrH}$ moderator. There are numerous other proposed designs in the literature (Angelo, 1985; El-Genk, 1994).

Given the need for a small reactor and shield mass, and a high conversion efficiency, we propose consideration of the following three options for the KBO mission: (1) a UZrH-fueled, NaK-cooled reactor with a steam Rankine conversion system, (2) a UN-fueled gas-cooled reactor with a recuperated Brayton conversion system, and (3) a UNfueled heatpipe-cooled reactor with a recuperated Brayton conversion system. Table 1 summarizes the key features for $100-\mathrm{kWe}$ systems. All three systems use the same assumed low-mass deployable thermal radiator to maximize the conversion efficiency. Subsequent sections describe the options in more detail, and examples for the KBO mission are given in a companion paper in this conference (Lipinski, 2000). There has not been sufficient detailing of the designs to perform an accurate weight estimate for each system, but rough estimates indicate that all of these systems have the potential to have specific masses less than $35 \mathrm{~kg} / \mathrm{kWe}$.

TABLE 2. Comparison of three electric power systems for the KBO mission.

\begin{tabular}{lccc}
\hline Component & $\begin{array}{c}\text { UZrH/NaK- } \\
\text { cooled/Rankine }\end{array}$ & $\begin{array}{c}\text { UN/gas- } \\
\text { cooled/Brayton }\end{array}$ & $\begin{array}{c}\text { UN/Heatpipe- } \\
\text { cooled/Brayton }\end{array}$ \\
\hline Electric power $(\mathrm{kW})$ & 100 & 100 & 100 \\
Thermal power $(\mathrm{kW})$ & 345 & 220 & 333 \\
Thermal efficiency (\%) & 29 & 46 & 30 \\
Nuclear fuel & $\mathrm{UZrH}$ & $\mathrm{UN}$ & $\mathrm{UN}$ \\
Primary coolant & $\mathrm{NaK}$ & $\mathrm{He} / \mathrm{Xe}$ & $\mathrm{Na}$ \\
Fuel clad material & Hastelloy & $\mathrm{Nb} / \% \mathrm{Zr} / \mathrm{Re}$ & $\mathrm{Nb} 1 \% \mathrm{Zr} / \mathrm{Re}$ \\
Vessel material & $316 \mathrm{SS}$ & $\mathrm{Super} \mathrm{Alloy}$ & $\mathrm{Mo}$ \\
Conversion cycle & Rankine & $\mathrm{Brayton}$ & $\mathrm{Brayton}$ \\
Energy conversion working fluid & water & $\mathrm{He} / \mathrm{Xe}$ & $\mathrm{He} / \mathrm{Xe}$ \\
Thermal radiator type & heatpipe/fin & heatpipe/fin & heatpipe/fin \\
Radiator working fluid & ammonia & ammonia & ammonia \\
Reactor coolant exit temp $(\mathrm{K})$ & 723 & 1200 & 1200 \\
\hline
\end{tabular}

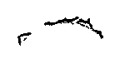




\section{ZrH-Fueled NaK-Cooled Reactor with Rankine Conversion System}

The SNAP series of reactors used UZrH fuel and a "thermal" neutron spectrum. That is, the neutrons released by fission were slowed down by collisions with the hydrogen in the fuel so that they could interact with the uranium more easily. This results in a minimum amount of fuel needed to achieve a self-sustaining reaction, which allows the reactor, and also the radiation shield, to be near minimum mass. The SNAP program produced six complete operating reactor systems at various power levels in the 1960s (Angelo, 1985). One system, SNAP-10A, was flown in space (see Figure 1).

The fuel type used in the SNAP series ( $\mathrm{UZrH})$ is the same as is used in numerous research reactors throughout the U.S. It was specifically designed for this class of research reactor because of its inherently safe response to temperature changes, automatically reducing the number of fissions if the reactor temperature increases. This feature also allows the system to adjust for load fluctuations without having to move any control elements.

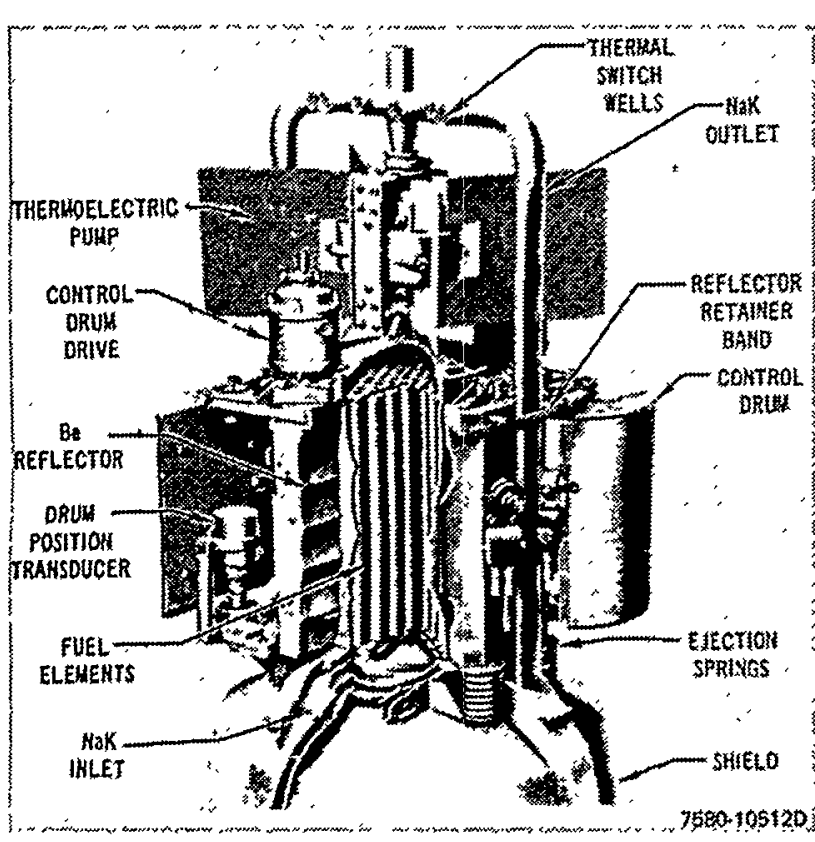

FIGURE 1. SNAP-10A Reactor

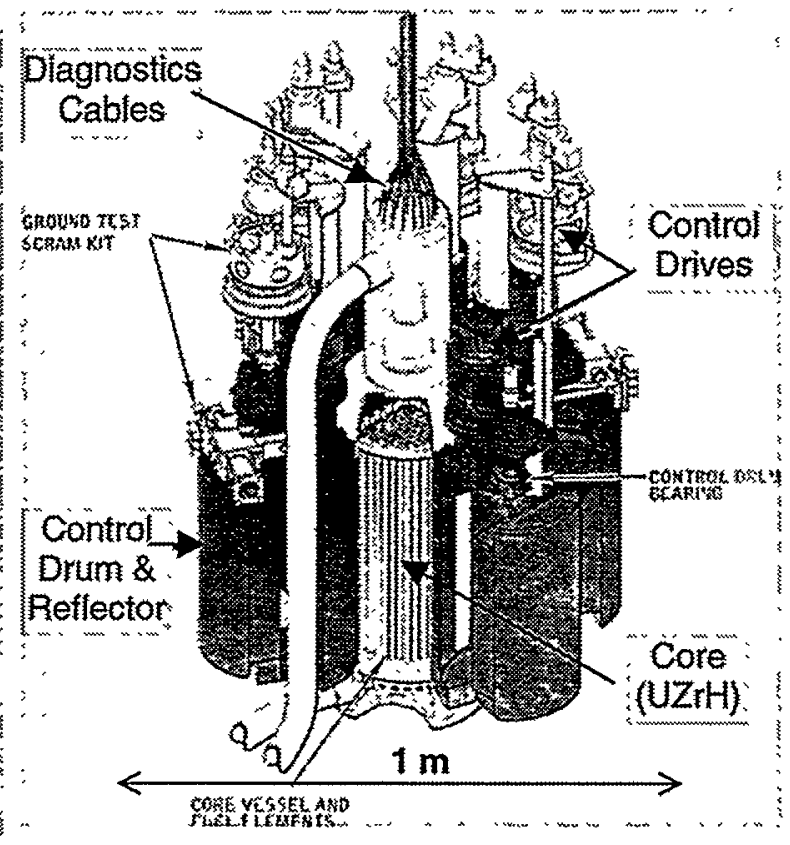

FIGURE 2. SNAP-8DR Reactor.

There were two SNAP reactors which produced $600 \mathrm{~kW}$ of thermal power ( $\mathrm{kWth})$ : SNAP-8ER and SNAP-8DR. The presently envisioned design would be similar to SNAP-8DR (see Figure 2). We would operate the reactor with a peak fuel temperature of only $800 \mathrm{~K}$ to extend the lifetime of the fuel. An enrichment of $93 \%$ is preferred, but a lower enrichment is also possible. The SNAP-10A spaceflight reactor and shield weighed about 268 and $98 \mathrm{~kg}$ respectively, summing to nearly $366 \mathrm{~kg}$. To allow for a larger power and total burnup capability, we estimate the reactor mass would be $500 \mathrm{~kg}$. To allow for shielding a large radiator, we estimate the shield would be $400 \mathrm{~kg}$.

UZrH fuel cannot be operated at as high a temperature as UN fuel. This necessitates the use of a low-temperature conversion system such as a steam Rankine conversion. Steam Rankine systems are a highly mature technology on earth with an extremely large industrial and extensive experience with reactor systems. However, they have never been tested or used in space, and this represents a major technical risk for this option. Figure 3 shows an overview of the conversion cycle. Heat is extracted from the reactor coolant $(\mathrm{NaK})$ and converted to steam. The steam drives a turbine as it expands, and then condenses at a heat exchanger connected to the thermal radiator. A pump recirculates the condensed water back to the boiler. The turbine, pump, and alternator are all on a single shaft floating on a liquid bearing. The system has one moving element. The radiator consists of many parallel and separate capillary pumped loops with ammonia as the coolant. The temperature increase in the steam generator 


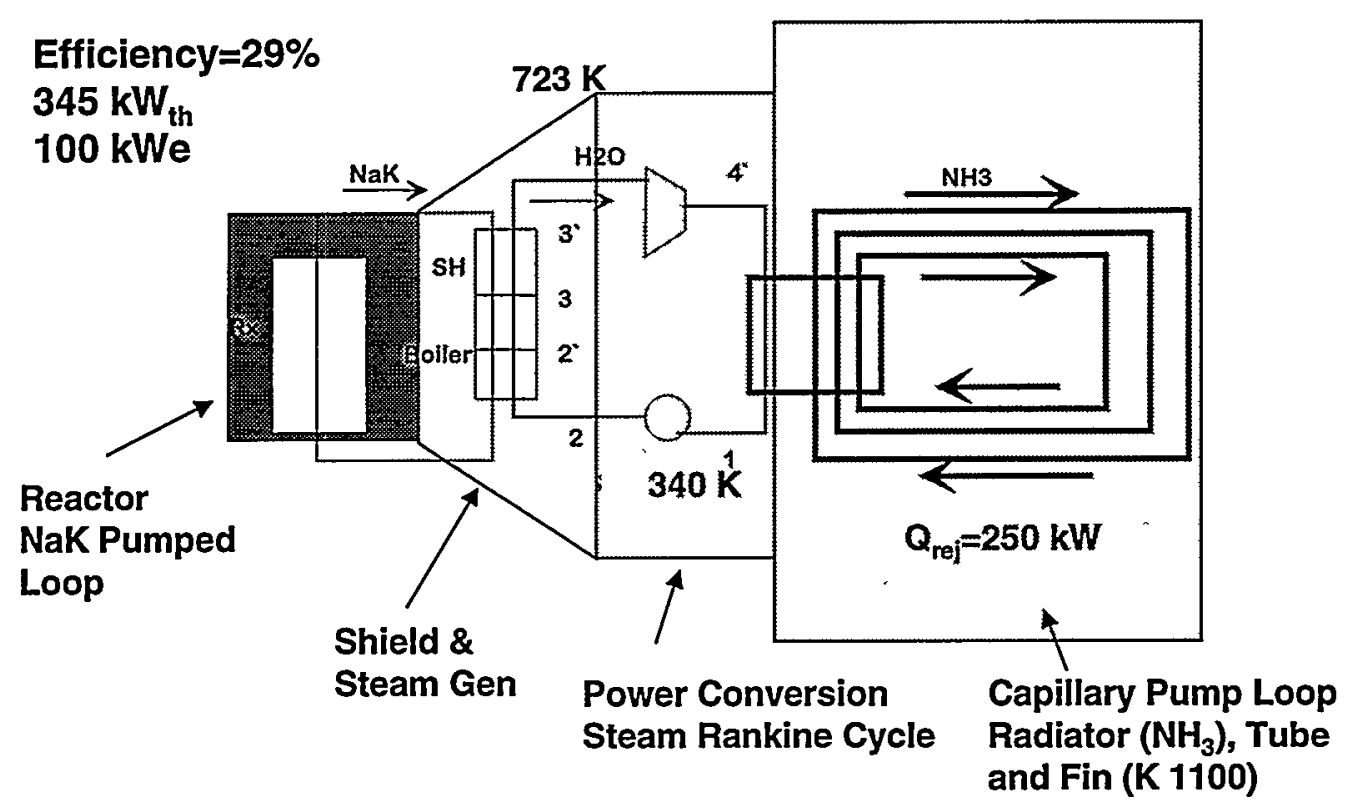

FIGURE 3. Overview of Rankine conversion system.

and superheater is about $383 \mathrm{~K}$, but the temperature increase in the reactor coolant can be considerably less by designing the steam generator appropriately.

The Department of Energy and NASA'a Jet Propulsion Laboratory developed operational hardware for a 25-kW toluene Rankine system driven by solar thermal energy (Nesmith 1985). The program also generated several conceptual designs for $100 \mathrm{kWe}$ systems. We estimate the weight of a TAP with a multi-stage turbine for the KBO mission would be about $90 \mathrm{~kg}$. The additional components for conversion system components (excluding the radiator) are estimated to be about $160 \mathrm{~kg}$, summing to a total of $250 \mathrm{~kg}$.

A major key to success for this system is development of a large lightweight (deployable) radiator. This allows heat rejection to space at a low temperature, which can result in a high conversion efficiency overall. NASA and commercial firms have been working on such radiators (some of the designs and specific diagrams are proprietary). The most advanced designs use an array of parallel capillary pumped loops with thermal fins between them. Ammonia is typically used as the coolant. The use of many separate loops minimizes the need for shielding from micrometeor impact. The total mass of these radiators is about $2 \mathrm{~kg} / \mathrm{m}^{2}$ (which would be $1 \mathrm{~kg} / \mathrm{m}^{2}$ of radiating surface if used in a flat configuration with two-sided radiation). Capillary pumped loops, loop heat pipes, and heat pipes have all been demonstrated in space, but these new lightweight radiator configurations have not.

The total radiating area needed for the baseline design is about $360 \mathrm{~m}^{2}$ at $330 \mathrm{~K}$. Traditionally space reactor radiators have been designed as conical with only the outside surface radiating. This was done to maximize the radiator area behind the radiation shield. However, to allow easier deployment of the radiator, to minimize the radiator mass, and to help reduce the shield mass, we presently envision the radiator as being flat with both sides radiating. Thus the physical radiator would be $180 \mathrm{~m}^{2}$ with a total radiating surface of $360 \mathrm{~m}^{2}$. The radiator would deploy from a manifold extending along the boom. With this potential design and the mass numbers quoted for small advanced systems as background, the radiator system is estimated to weigh $360 \mathrm{~kg}$.

The sum of all these estimated weights (reactor, shield, conversion, radiator) is $1510 \mathrm{~kg}$. Structure, additional controls, other components, and contingency will add to this total estimate, but staying below the $2350 \mathrm{~kg}$ limit seems achievable.

\section{UN-Fueled Gas-Cooled Reactor with Brayton Conversion System}


The most recent U.S. space reactor power program, SP-100, developed detailed designs, advanced reactor fuel, a "zero-power" reactor critical assembly, radiation-hardened control drives, and various other hardware components in the 1980s. The baseline SP-100 was designed to produce $2400 \mathrm{~kW}$ thermal and $100 \mathrm{~kW}$ electric with a lifetime of 7 to 10 years (Mondt, 1994, Mondt 1995, El-Genk 1994). The projected specific power at program termination was about $42 \mathrm{~kg} / \mathrm{kWe}$. It used a high-temperature advanced fuel (UN) which was developed and proven with nuclear burn-up tests during the program. The fuel was not designed to slow down the fission neutrons, so the neutron spectrum was "fast" and the resulting core size and U-235 mass for the reactor to achieve criticality was thus larger than for the SNAP series.

The proposed design consists of a gas-cooled fission reactor with a closed Brayton cycle for power conversion at $100 \mathrm{kWe}$. The main difference is replacement of the $4.2 \%$ efficient thermoelectric conversion system with a closed Brayton cycle and generator to obtain about $46 \%$ conversion efficiency. Such a high efficiency is achieved by using a large thermal radiator, which allows a lower thermal sink temperature. There is a very extensive industrial data base and fabrication experience for open-cycle Brayton units: they form the basis for commercial and military jet engines as well as helicopter engines. Brayton conversion systems have one moving part: a single shaft connected to the turbine, the electrical generator rotor, and the compressor. In closed systems, this single shaft floats on a gas bearing bled off from the main gas flow and returned to it. A 52,000-hr ground test of a 10.7-kWe closed Brayton unit was conducted at NASA/LeRC in 1965.

The reactor is gas cooled ( $30 / 70$ mole- $\% \mathrm{He} / \mathrm{Xe}$ ) to couple better with the Brayton system. The fuel is uranium nitride (UN), which is the same fuel extensively tested for longevity in the SP-100 program. The active core is 0.40 $\mathrm{m}$ in diameter and $0.5 \mathrm{~m}$ long. The radial reflector is $0.15-\mathrm{m}$ thick beryllium, and the axial reflector is $0.10-\mathrm{m}$ thick $\mathrm{BeO}$. The fuel rods are held in a lattice of $\mathrm{BeO}$, which provides a small amount of moderation. There is a strong negative thermal feedback which allows the reactor power to naturally follow variations in load without needing adjustment of the control elements.

Figure 4 shows a schematic of the Brayton cycle and the associated state points. The reference design produces 100 $\mathrm{kWe}$ with $46 \%$ total thermal efficiency and has a specific mass of about $26 \mathrm{~kg} / \mathrm{kWe}$. A key feature is the heat

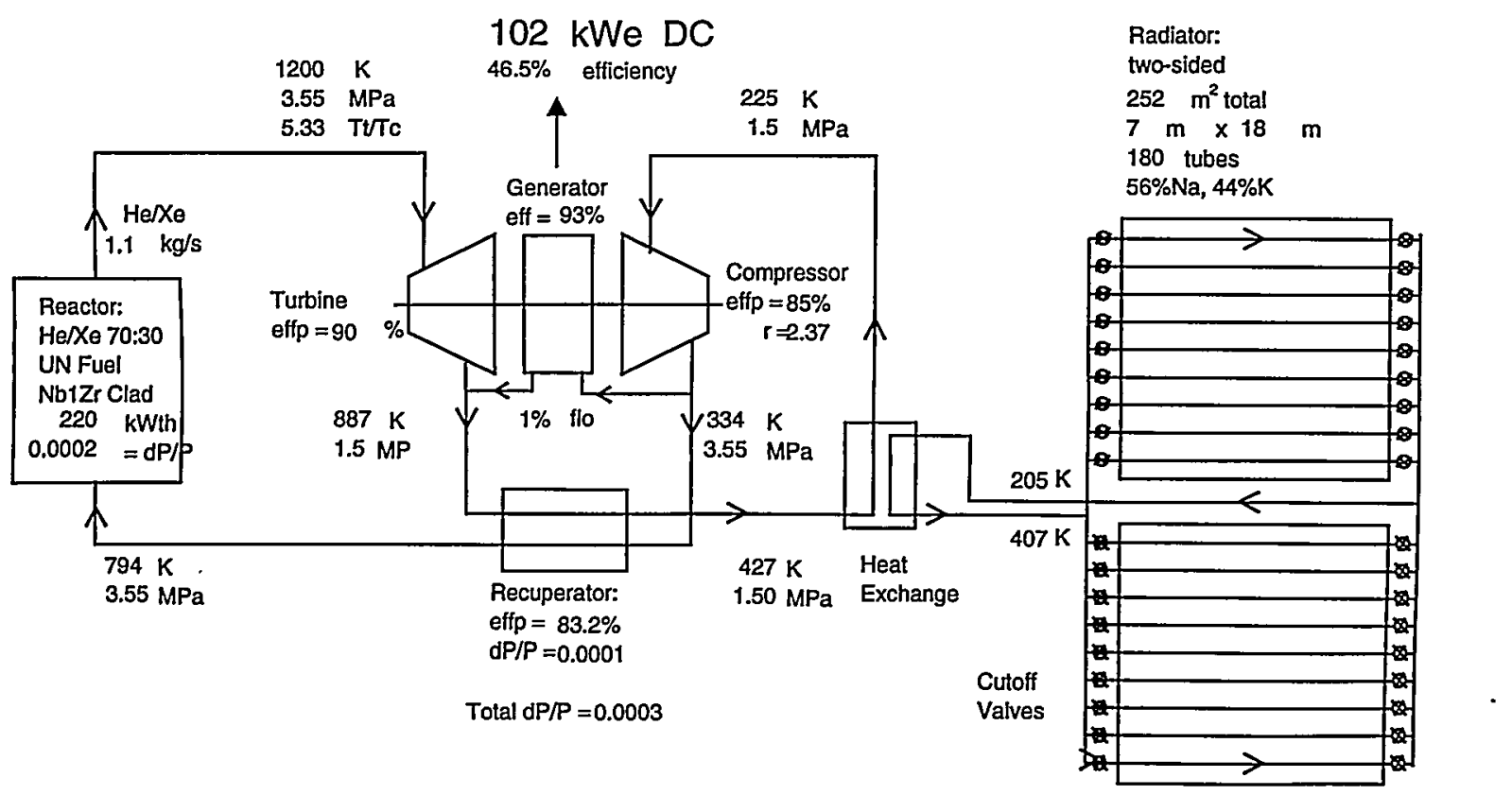

FIGURE 4. Brayton cycle schematic and associated state points.

exchanger which recuperates some heat from the turbine exit and uses it to preheat the gas returning from the heat sink before it re-enters the reactor. This recuperation step gives the cycle a greater conversion efficiency than a 
"non-recuperated" Brayton cycle. The radiator is opened out flat to radiate from two sides and is $126 \mathrm{~m}^{2}$ per side. This allows a low heat-sink temperature and enables the high electrical conversion efficiency. Detailed weight estimates are not available for this configuration, but the larger reactor size will likely make it heavier than the UZrH Rankine system.

\section{UN-Fueled Heatpipe-Cooled Reactor with Brayton Conversion System}

Houts, Poston, and Emrich have reported on various designs for heatpipe cooled reactors (Houts, 1998; Poston, 1996). In the heatpipe power system (HPS) heatpipes are inserted into the reactor core at regular locations to remove heat by boiling and wicking of the coolant. This heat is then transferred via a heat exchanger to the working fluid of a conversion system. For our application, we would use UN fuel in the reactor, sodium in the heat pipe, and $\mathrm{He} / \mathrm{Xe}$ in the Brayton conversion system. Thus the system state points would be very similar to the gas-cooled Brayton system. Figure 5 shows a fuel/heatpipe module and a cross section of the reactor.

There are numerous advantages and features of the HPS that make it an attractive near-term system:

1. Safety. The HPS is designed to be subcritical for all credible launch accidents.

2. Reliability. The HPS has no single-point failures.

3. Long life. The design lifetime is in excess of 10 years.

4. Modularity. The HPS consists of independent fuel/heatpipe modules which can be tested individually.

5. Testability. The HPS system launch hardware can be tested at full power using electrical heaters in place of fuel rods. Unirradiated fuel rods inserted before launch. Full-power nuclear tests might not be required.

6. Versatility. The HPS can use a variety of fuel forms, structural materials, coolants, and conversion systems.

7. Scalability. The HPS design scales well to beyond $1000 \mathrm{~kW}$ thermal power.

8. Simplicity. There are few system integration issues since there are no in-core shutdown rods, no hermetically sealed refractory metal vessel or flowing loops, no electromagnetic pumps, no coolant thaw systems, no gas separators, and no auxiliary coolant loop for decay heat removal.

9. Fabricability. Most of the fabricated parts are small modules with similar metals; there is no pressure vessel.

10. Near Term. The system needs no development of advanced materials or components. It can be developed quickly and inexpensively with few nuclear tests.

11. Low Mass. The HPS system has a high fuel fraction in the core since it uses no in-core shutdown rods. The potential for in-space fueling (because of no pressure vessel) allows a more compact form while still meeting launch safety requirements.

\section{LAUNCH APPROVAL}

There is a precedent for operating small research-sized reactors in space. There are presently over 30 shut-down nuclear reactors orbiting earth at about $600 \mathrm{~km}$ altitude. All but one of these are Russian reactors from Rorsat highpower radar satellites. The one U.S. reactor is SNAP-10A, launched in 1965. Every U.S. launch of a payload involving nuclear material must be reviewed by an Interagency Nuclear Safety Review Panel (INSRP) (Sholtis, 1994). The INSRP reviews the sponsors assessment of the risk and reports to the Office of Science and Technology Policy under the Executive Branch. The President or his designee (usually the Science Advisor) then decides whether to grant launch approval. This process has been followed for 25 launches of nuclear materials over the past 40 years and approval has always been granted. All but one of these launches have involved radioisotopic power sources, but a space reactor would follow the same process. 

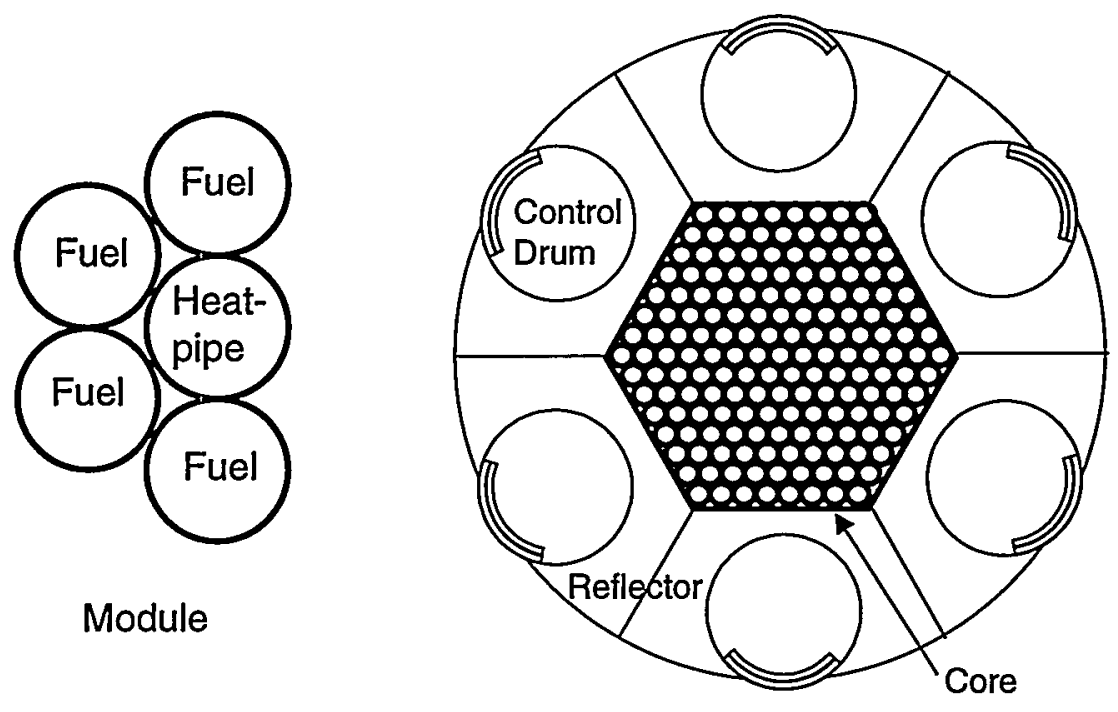

FIGURE 5. Module and reactor for heatpipe power system.

One key safety feature of a fission reactor is that it is barely radioactive before it is used. The radiological inventory in the fresh fuel is about the same as a truckload of uranium ore, with which uranium miners work safely in nations around the world. The space reactor can be tested prior to launch at essentially zero power to prevent any inventory buildup, so the primary concern for launch safety will be to assure that the reactor will not turn on for any conceivable launch accident scenario. This requires solid engineering, but is not difficult. In addition, once the reactor begins operation in space, it should be assured that it cannot reenter the earth's atmosphere. With high circular orbits and low-thrust ion-propulsion, this should be fairly straightforward. Once it is on its way away from earth, the safety issues vanish, and waste disposal is automatic.

\section{POTENTIAL FOR INTERSTELLAR FLIGHT}

To have ready access to nearby stars with travel times less than a few years will require speeds faster than the speed of light and "breakthrough" physics. We may all hope for that future day, but in the meantime, we should consider what is feasible using known laws of physics and extrapolations of present-day technologies.

For journeys far outside the solar system, the effect of the sun's gravity and the orbital velocity of the earth may be neglected. Then, for a spacecraft with electric thrusters running at a steady constant power, derivation of the velocity and distance traveled in a given time of thrusting is simply a matter of integrating equation (2) with $m_{d}$ replaced with the total mass (including propellant), which is time dependent. The final velocity $\left(v_{b}\right)$ after a total thrusting time (or "burn" time) of $t_{b}$ and the distance the spacecraft has traveled (d) after thrusting for that duration and then coasting for an additional duration of $t_{c}$ are:

$$
\begin{gathered}
v_{b}=g I_{s p} \ln \left(\frac{t_{b}}{\tau}+1\right), \\
d=g I_{s p}\left(t_{b}-\tau \ln \left(\frac{t_{b}}{\tau}+1\right)\right)+v_{b} t_{c} .
\end{gathered}
$$

Here $\tau$ is a characteristic time which is equal to the time that it takes for the thrusters to consume an amount of propellant equal to the total dry mass of the spacecraft: 


$$
\tau=\frac{m_{d}\left(g I_{s p}\right)^{2}}{2 \eta P}
$$

Note that equation (3) is the classical rocket equation in a different form. There is an optimum Isp which results in a maximum $d$ for a given set of $t_{b}, t_{c}, \eta, P$, and $m_{d}$.

We may use these relations to estimate what performance fission-based systems might be able to deliver. Since travel to the nearby stars without new physics is extremely challenging, we will allow a leisurely 200 years for the total mission. Figure 6 shows the total distance traveled after 200 years for various burn durations up to 50 years; the final velocity after 50 years of burn is also shown. The various curves represent different total specific masses for the spacecraft without propellant $\left(\mathrm{m}_{\mathrm{d}} / \mathrm{P}\right)$. Fission power systems at the 1-MW level using present technology should be able to reach $10 \mathrm{~kg} / \mathrm{kWe}$, and higher-powered systems with more advanced reactors and conversion systems should be able to reach 1 or $0.1 \mathrm{~kg} / \mathrm{kWe}$. A very large system with advanced technology might reach $0.01 \mathrm{~kg} / \mathrm{kWe}$. Each curve has a fixed specific impulse which was chosen to maximize the distance traveled for most of the span of the curve.

The figure shows that this technology can bring us a long distance toward interstellar flight. The number of AUs indicated on the right side of the figure is very large and shows just how far this system can penetrate very deep space. That we can even envision travel to a light year without tapping a large fraction of earth's resources and without postulating nation-sized propulsion systems is also impressive. The burn time is not unreasonable; terrestrial reactors are expected to last about 50 years. Refueling the reactor can be accomodated by inclusion of replacement nuclear fuel in the determination of the dry mass. Or, it may be considered as part of the overall "propellant", thrown overboard at zero velocity, and averaged in with the electric-propulsion propellant velocity to yield an effective specific impulse. The same can be done for the electric thrusters which would need replacement. (Most of the curves resulted in about five dry masses worth of propellent being consumed.) The specific impulses are challenging but not unreasonable for large systems.

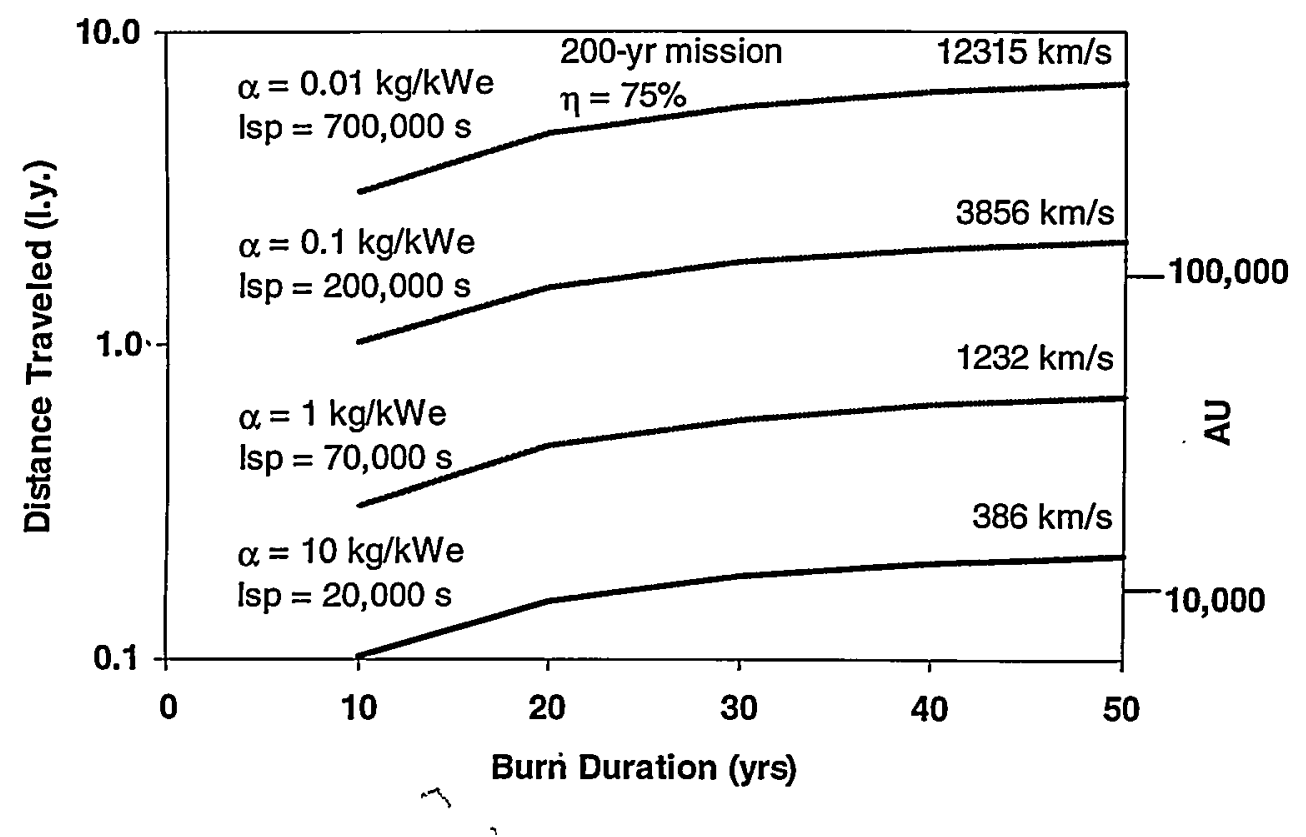

FIGURE 6. Distance traveled in 200 years by a fission-powered electric-propulsion spacecraft. 


\section{SUMMARY}

Three possible power sources for a fission-based electric propulsion system are described: (1) a UZrH-fueled, NaKcooled reactor with a steam Rankine conversion system, (2) a UN-fueled gas-cooled reactor with a recuperated Brayton conversion system, and (3) a UN-fueled heatpipe-cooled reactor with a recuperated Brayton conversion system. All three of these systems have the potential to meet the specific mass requirements for interstellar precursor missions capable of $100 \mathrm{~km} / \mathrm{s}$ in the near term. Advanced versions of a fission-based electric propulsion system might travel as much as several light years in 200 years.

\section{ACKNOWLEDGMENTS}

This activity supported by Sandia National Laboratories. Sandia is a multiprogram laboratory operated by Sandia Corporation, a Lockheed Martin Company, for the United States Department of Energy under Contract DE-AC0494AL85000.

\section{REFERENCES}

Anderson, R. V., et al, Space-Reactor Electric Systems: Subsystem Technology Assessment, ESG-DOE-13398, Rockwell International, Canoga Park, CA, chapter IV, 1983.

Angelo, Jr., J. A. and D. Buden, Space Nuclear Power, Orbit Book Co., Inc., Malabar, Florida, pp. 159-176, 1985.

Chang Diaz, F. R., "Recent Progress in the VASIMR", 1998 Div. of Plasma Physics Meeting, Nov. 16-20, 1998, New Orleans, $L A, 1998$.

El-Genk, M., A Critical Review of Space Nuclear Power and Propulsion, 1984-1993, M. S. El-Genk, Ed., U. of New Mexico Intitute for Space Nuclear Power Studies, Albuquerque, NM, AIP Press, New York, NY, 1994.

Houts, M. G., D. I. Poston, and W. J. Emrich, Jr., "Heatpipe Power System and Heatpipe Bimodal System Development Status", Space Technology and Applications Internations Forum 1998 (STAIF-98), January, 1998, Albuquerque, NM, pp. 11891195, 1998.

Jewitt, D. C., "Kuiper Belt Objects," Annual Review of Earth and Planetary Sciences, 27, 287-312. (1999).

Lipinski, R. J, R. X. Lenard, S. A. Wright, M. Houts, B. Patton, and B. Poston, "NEP for a Kuiper Belt Object Rendezvous Mission," Space Technology and Applications Internations Forum 2000 (STAIF-2000), January, 2000, Albuquerque, NM, Session E3, 2000.

Malhotra, Renu, "Migrating Planets," Scientific American, 281, No. 3, 56-63 (1999).

Mondt, J. F., Truscello, V. C., and Marriott, A. T., "SP-100 Power Program," in Eleventh Symposium on Space Nuclear Power and Propulsion, Albuquerque, NM 1995, M. S. El-Genk, Ed., U. of New Mexico Intitute for Space Nuclear Power Studies, Albuquerque, NM, AIP Press, New York, CONF 940101, 1995 , pp. 143-155.

Mondt, J. F., V. C. Truscello, A. T. Marriott, "SP-100 Power Program," 11th Symp. on Space Nuclear Power and Propulsion, Albuquerque, Jan 1994, CONF-940101, pp. 143-155, 1994.

Nesmith, B., Bearing Development Program for a 25-kWe Solar-Powered Organic Rankine-Cycle Engine, DOE/JPL-1060-92, Jet Propulsion Laboratory, Pasadena, CA, 1985.

Polk, J., Anderson, J.R., Brophy, J.R, Rawlin, V. K, Patterson, M.J., and Sovey, J.S., "The Effect of Engine Wear on Performance in the NSTAR 8000 Hour Ion Endurance Test," Joint Propulsion Conference, Cleveland, OH, July 14, 1998, AIAA 97-3387, 1998.

Poston, D. I. and M. G. Houts, "Nuclear and Thermal Analysis of the Heatpipe Power and Bimodal Systems", Space Technology and Applications Internations Forum 1998 (STAIF-96), January, 1996, Albuquerque, NM, pp. 1083-1093, 1996.

Sholtis, Jr., J. A., Connell, L. W., Brown, N. W., Mims, J. E., and Potter, A., "U. S. Space Nuclear Safety: Past, Present, and Future," in A Critical Review of Space Nuclear Power and Propulsion 1984-1993, M. S. El-Genk, Ed., U. of New Mexico Intitute for Space Nuclear Power Studies, Albuquerque, NM, AIP Press, New York, NY, 1994, pp. 269-304.

Sutton, G. P. Rocket Propulsion Elements, An Introduction to the Engineering of Rockets, Fifth Edition, New York, NY, John Wiley \& Sons , 1986, pg. 99.

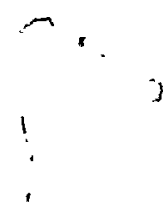

